\title{
CHALLENGES TO A MULTICULTURAL SOCIETY HIDDEN REALITIES AS BIAS FACTORS OF INTEGRATION
}

\author{
Michaela Frank \\ Private University College of Education of the Diocese of Linz
}

\begin{abstract}
The aim of the presentation is deepening the understanding of one's own heritage, cultural roots and behaviours. Hidden realities start with ourselves as long as we are not conscious of our own cultural constructs. Not knowing them inevitably leads to failures in understanding people with different nationalities. A discourse is initiated which is based on the following selected topics: (1) emotionality, (2) transgenerational transmission and (3) language in dependence on mediation by third persons. Practical experience is linked together with scientific knowledge to increase sensibility for multicultural phenomena contributing to a better understanding for ways of integration.
\end{abstract}

Keywords: cultural roots, cultural bias, emotionality, interpreting, stress, transgenerational transmission, trauma transmission.

\section{Introduction}

When working within a cultural context it is always good to declare one's points of views in preventing misunderstanding in advance. I do not only talk about culturally specific topics; I also present in another academic tradition. This means I consciously expose you to another cultural event. The following three topics have been chosen because they all are dealing with communication (Ellworth, 1994).

Emotions are expected to be universal; in everyman's life there are experiences which might be shared all over the world. In conclusion people understand each other because of this fact. Feelings might be the same but their presentation is depending on culture specific developments. Equally the regulation of emotion is an issue of developmental psychology. Sometimes emotions pop up in intensities not adequate to the situation. There could be repeatedly nightmares leading to exaggerated emotional conditions where the affected does not have any clue about the reason, the contents of the dreams as well as their emotions being unclear to the individual. Explanations are to be found e.g. in inquiries of second generation after Holocaust (Frankl, 1959).

Transgenerational transmission. Kellerman (1999) shows the psychological causes of non verbally transmitted incidents on the succeeding generations. Although these phenomena have been well documented on Holocaust victims, one might observe refugee families exhibiting similar behaviours. Most of them having undergone a history of torture and traumatic experience. It might be worth to consider the effect of traumatic transgenerational transmission to show up at a lower traumatic exposure than the Holocaust presented. This is followed by a discussion on verbal communications problems which may show up when working with an interpreter (Friedlmeier, 2013). 


\section{Emotionality}

The way emotions are experienced and presented are culture - specific (Ellworth, 1994). The Two American citizens, for example who were already born in the USA made their feeling on sadness transparent. Even though their appearance did not imply any hint of their ethnic background their designs and aesthetic concepts refer to different cultural expressions.

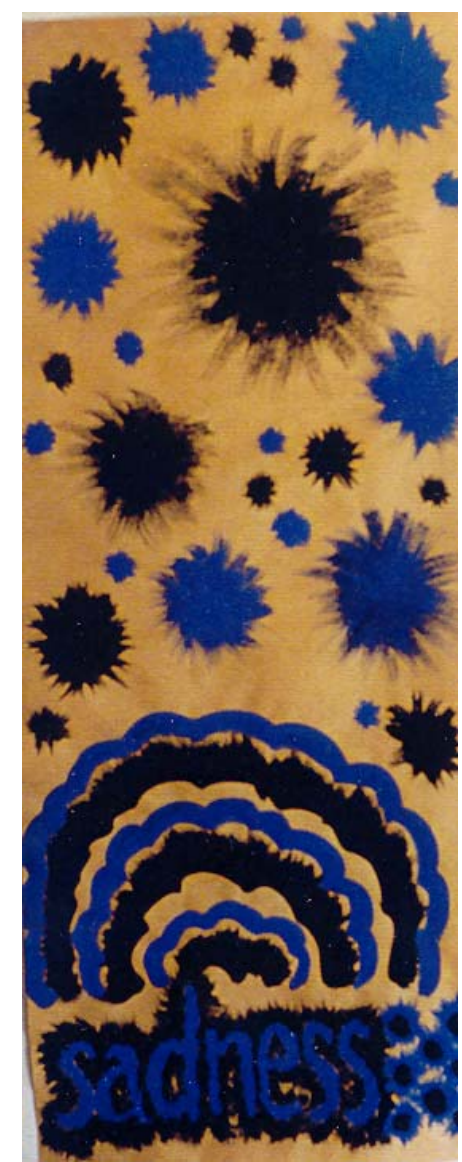

Fig. 1 Sadness: done by man of Chinese origin

Trauer: Darstellung von einem Mann chinesischen Ursprungs

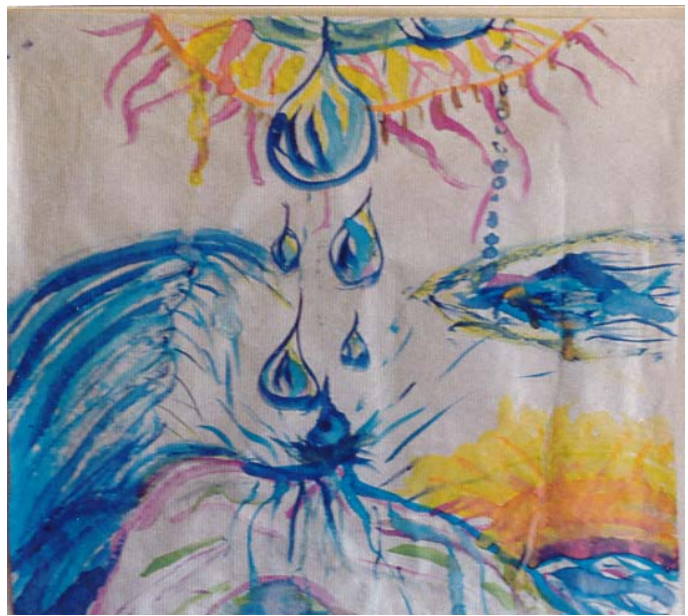

Fig. 2 Sadness done by man of Caucasian origin Trauer: Darstellung von einem Mann kaukasischen Ursprungs

The following writings use Greenfield's and Keller's (2004) term of culture whereby culture is defined as a system of shared believes and shared every day life practices. It is furthermore also valid for people living in comparable socio economic status and agreed on the same values and norms. What is the biological basis and what are the culture bound expressions of emotions? Matsumoto and Hwang (2011) conclude not all affective states should be identified by emotions. They suggest certain domains more or less influenced by culture or biology to be distinguished in further developments. Culture comparing research focuses mainly on acknowledging of emotions and 
the emotional expression. The connection between emotion and the regulation of it e.g. stress and coping are almost never looked upon (Friedlmeier, 2013).

The emotional perception and presentation develops in a mother - child interaction. If the mother reacts on positive signals of the child and by strengthening or if confronting the difference important as it is in dependence on cultural norms ( Keller, 2003).

This is provides certain behaviours in case of an immigration. Lamm (2013) talks about opposing styles of education, which on one hand foster the autonomy of the individual in having trust in yourself, self esteem and the ability to be competitive (child centred model of education). On the other hand social bonds are of greatest importance. The child is to be prepared for a hierarchical socialized group. People sharing the same self concept belong to the same cultural group. This is the basis for future ways to deal with stress symptoms e. g. the stimulus and stimulus answers. In systems where the goal of education is an individual personality the display of feelings is wanted. This also means one can expect low control of emotions. Is the functioning of a social network in the focus then it is important to gain only low arousal states and this to be interpreted as positive behaviour. The ability to control emotions is central in this model. Adaptation and execution is to be seen together with the development of emotions. In a hierarchical system this is seen as mark for adaptation (Spangler \& Grossmann, 1993).

Not to consider these developmental und psychological differences evokes biases based on cultural judgements.

\section{Transgenerational transmission}

Transmission in general means to pass on information from one individual to the other or from group to group. Nauck (2001) defines cultural transmission as a phenomenon of a culture contact situation. Cultural transmission consists of a vertical and a horizontal part which includes personality traits, cognitive development attitudes, patterns of socialisation, gender issues, religious believes, behaviours and so on. At least there is a dual inheritance model that is responsible for genetic and cultural transmission (Laland, 1993).

Transgenerational transmission is discussed in this paper as a passing on of unconscious content to the next generations. Cultural transmission screens out individual as well as collective social historical events, mainly trauma. This specific type of cultural transmission is very well documented with Holocaust survivors and their families.

Nevertheless most of the described phenomena are to be seen in refugees and their offspring who often have been torture victims. Terrifying nightmares of tortures and dead people emerge generations later in dreams of individuals who have no idea of what had happened to their ancestors. Life threatening events are unconsciously transmitted and show specific effects to the next generations. The 
more it is in the unconscious, the more the unconscious content is destructive to the individual.

People working in social or mental health settings may easily judge mental personality disorders whereas specialists may feel pathologizing might be inadequate. According to Frankl (1959) is people's reaction to an abnormal situation is normal behaviour. Although an enormous variety of different traumas and stressors the human responses to them are similar (Weisaeth \& Eitinger, 1993 ,

Kellerman (2013) distinguishes between the following presentation clusters: The Holocaust Survivor Syndrome, the Child Survivor Syndrome and the Second Generation Syndrome.

The Holocaust Survivor Syndrome:

Persistent anxiety, fear of renewed persecution, chronic depression, psychosomatic symptoms of concentration and memory difficulties, maladjustment, sleep disturbances terrifying nightmares and a general difficulty to verbalize their traumatic experience, guilt for having survived.

The Child Survivor Syndrome:

There are different diagnostic pictures dependent on the age. Children up to adolescence show dissociation, psychic numbing and denial as references to severe trauma exposure. There is a high vulnerability with high risk for emotional instability and distress. Interpersonal relationships are impaired by suspicion and distrust. Personality disorders and developmental impairment are regular manifestations.

\section{The Second Generation Syndrome}

The Self shows an impaired self esteem with persistent identify problems, over identification with parents "victim status. A need to be super achievers to compensate for parents' loss, carriers the burden of being "replacements" for lost relatives. They expect catastrophies, are preoccupied with death, stress to Holocaust stimuli, and are dominated by fantasies of traumatic Holocaust experiences. Annihilation anxiety, nightmares of persecution, dysphoric moods connected to feeling of loss and mourning. Unresolved conflicts around anger complicated by guilt. Exaggerated family attachments - symbiotic ones -, dependency and difficulties in entering into intimate relationships and in handling interpersonal conflicts"

Kellerman (1999) suggests introducing a new category of diagnosis namely: Transmitted Trauma Syndrome.

In general the concepts of transmission are already recognized by systemic family therapy. There are life stories to be found with family reconstructions. Transmission is also valid for aesthetic concepts being culture bound. The question arises if there is only an aesthetic tradition transmitted or are there other cultural implications to be recognized?

This is to be demonstrated by an art therapy session. One day the client B. came in and says:" I am in a thousand pieces and split all over the place". The expected 
incident had also come: she was discovering her boy fried would not come to marry her. (This was a delusional content, the boyfriend did not exist). Facing the fact my client was decompensating - a critical situation. I made a circle. There is a common praxis which usually works. Afterwards I asked her if it would be possible to bring all the pieces together and to put them into the circle. A heart with knife emerged. In exploring the painful content she suddenly decided to sit down on here painting. Then she started to fall into whipping movements. (While witnessing the process thoughts of Native American healing ceremonies emerged: The Navajos make their sick people sit down on a painting which has already been prepared before in a preparation by their medicine man lasting for hours. Then the whole community builds a circle around and sing for hours). Suddenly her hand started to move forward. I asked her to exaggerate the gesture. What was with her hand? "I can never get a helping hand!" I therapeutically intervened with being surprised: "I do not really understand? We shake hands any time you come and any time you leave! So what?" She looked at me and repeated her words. I made her making shake hands for several times. Then I realized a change in the expression in her face. She stated:" This is when I feel whole." She drew the following pictures.

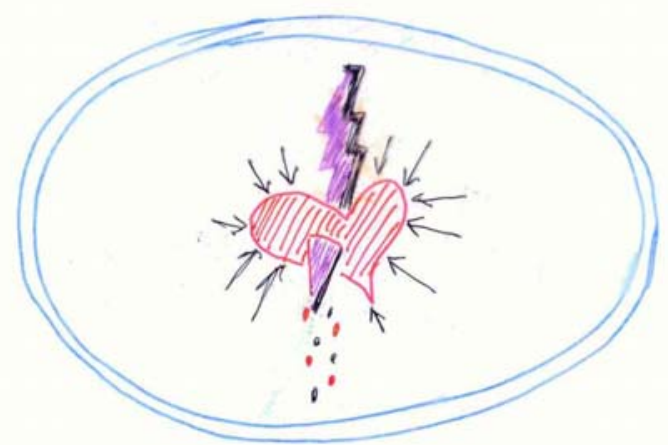

Fig. 3 Scetch of therapist: "I put the pieces together" Skizze der Therapeutin: "Ich habe die Stücke zusammen gebracht"

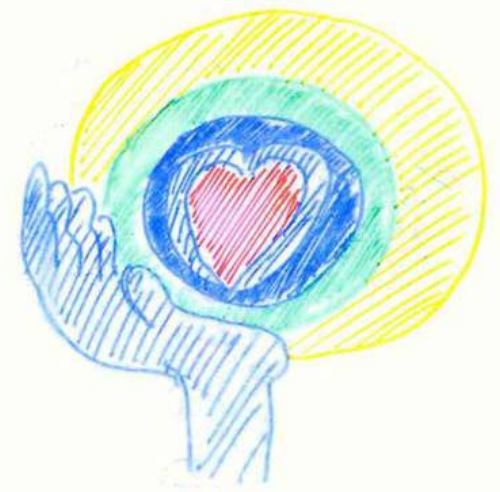

Fig. 4 Scetch of therapist: "This is when I feel whole" Skizze der Therapeutin: "So ist es, wenn ich mich ganz fühle" 
The delusions did not show up for another two months. During this period she was able to face traumatic issues which had been unconscious before. It also turned out later her great grandfather had been Native American.

It might be worth a discussion to see her behaviour as a transgenerational transmission of inherited culture. Conceptualizing this phenomenon as a regression opens up to the possibility of people regressing not only within family issues but also within cultural societal contexts. This would also imply (projected) changes in the helper's role and the task is to be sensitive to these changes, for help and healing depend on cultural `s role expectations (Tseng \& Streltzer 1997).

\section{Language mediated by third persons}

One can state: there is very few literature on this crucial practical part of intercultural contact. Nevertheless there is a need to bring this topic into discussion. To overcome language barriers it might often be necessary inviting an interpreter. Often family members serve that role, which makes the process more complicated because they do not only take on the tasks of translation but also try to convey needs or keep the secrets of the family. (Tseng \& Strelzer, 1997).

The writings below are based on ten years 'work in a psychotherapy project for refugees and migrants in Austria. Interpreters are not professionals and rarely trained for the work in the social and mental health system. The interpretation itself usually embraces best three languages very commonly four. For example: The client is from Aserbaidschan, the interpreter Bulgarian and the therapist Austrian. The client and the interpreter use Russian. That means there is a big loss in language communication (four languages!). Additionally the language used for communication between interpreter and client might bring up difficult memories itself. It might be the aggressor's language. Many of the interpreters also have a history of flight themselves and have been traumatized. It happens that the interpreter says: Sorry I can't translate this. Then the therapist must quickly decide if there is a psychological problem of the interpreter or a language problem. Many of the interpreters have a history of flight and have been traumatized themselves. When the story of the client evokes memories of the interpreter or a societal taboo than the interpreter experiences speechlessness. In this situation the therapist needs to come up with a solution like talking the problem trough or translate word per word (then the interpreter's psyche might not be able for sense grasping). It is not possible to exchange the interpreter because of established trust and confidence by the client, but also to keep the interpreter's private sphere confidential. The challenge of this situation is that there are two individuals who need to be taken care of and to be at the edge of decompensating. The main focus within this triad is on the interpreter, because the psychological issues of the client are mainly known, the ones of the interpreter show up first within the session. Best would be a bilingual, be cultural therapist, but this is rarely to be found. 


\section{Conclusions}

Culturally specific questions in the realm of emotionality show a practice of low differentiate considerations which facilitate biases. An increase in openness and sensitivity towards emotional activities is to be wished for. An increase of sensitivity of being with emotions and affects would be a step forward. Multicultural training would be helpful. The theoretical underpinnings of these unconscious phenomena might be helpful to fully understand people. Although (unconscious) transgenerational transmission had been examined, experiences make one conclude the observed phenomena could provide a evidence on a more general level. Inquiries in this field would be necessary. The description of Child Survivor Syndrome and the Second Generation syndrome enable professionals to come to a better understanding for refugees, migrants and their families; they might find help and it prevents cultural biases. Talking about the interpreters they are the group in danger. It is an important task to make inquiries on language encounters. Some parts of the paper refer to the usefulness of creative work in deciphering cultural contents. Creative tools as part of intercultural communication might be worth considering.

\section{Summary}

When working within a cross cultural setting the situation might easily lead to misunderstanding. Using the same word doesn't implicit people's meaning and talking are the same because non verbal and verbalized emotional states are defined by their developmental conditions of their cultures. These differences also influence the adaptation mechanism and coping strategies of stress. For example unconscious transgenerational transmission is one of these coping styles to be seen as a reference so severe trauma. Based on inquiries of Holocaust's victims specific syndromes are described. They provide tools to understand social relationships of refugee and migrant families. At least the most important tool in communication which is language is brought into discussion and the difficult work with the interpreter is highlighted. Cultural sensitivity, training and research are necessary to overcome cultural barriers and prevent biases based on them.

\section{Biblography}

1. Ellworth, P.C. (1994). Sense, culture and Sensibility. In S. Kitayama \& H.R. Markus (Eds.), Emotions and culture. Empirical studies of mutual influence (pp. $23-50$ ). Washington, DC: American Psychological Association.

2. Frankl, V. (1959). Man `s seach for meaning. Boston: Beacon.

3. Friedlmeier, W. (2013). Emotionen im Kulturvergleich: eine entwicklungspsychologische Perspektive. In P. Genkova, T. Ringeisen \& F. T. L. Leong (Hrsg.), Handbuch Stress und Kultur. Interkulturelle und kulturvergleichende Perspektiven (pp. 217 - 238). Wiesbaden: Springer. 
4. Greenfield, P.M. \& Keller, H. (2004). Cultural psychology. In C.D. Spielberger (Ed.), Encyclopedia for applied psychology. Oxford, UK: Elsevier.

5. Keller, H. (2002). Development as the interface between biology and culture: A conceptualization of early ontogenetic experiences. In H. Keller, Y. Poortinga, \& A. Schölmerich (Eds.), Between culture and biology (pp. 215 - 240). Cambridge, England: Cambridge University Press.

6. Kellerman, N. P. F. (2013, 14. 2. 20013). Diagnosis of Holocaust survivors and their children. URL www.peterfelix.weebl.com/publication.html.

7. Lamm, B. (2013). Entwicklung im kulturellen Kontext: Entwicklungspfade der Emotionsregulation. In P. Genkova,T. Ringeisen, \& F. T. L. Long (Hrsg.), Handbuch Stress und Kultur. Interkulturelle und kulturvergleichende Perspektiven (pp. 81 - 95). Wiesbaden: Springer.

8. Laland, K.N. (1993). The mathematical moldelling of human culture and its implications for psychology and the human sciences. British Journal of Psychology, 84, $145-169$.

9. Matsumoto, D.,\& Hwand, H.S. (2012 ). Culture and Emotion: The integration of biological and cultural contributions. Journal of Cross - Cultural Psychology, 43(1), 91 11.

10. Nauck, B. (2001). Intercultural contact and intergenerational transmission in immigrant families. Journal of Cross - cultural Psychology, 32 (2), 159 - 173.

11. Schönpflug, U. (2001). Introduction. Cultural transmission. A multidisciplinary research field. Journal of Cross - Cultural Psychology, 32 (2), 131 - 134.

12. Spangler, G. \& Grossmann, K.E. (1993). Biobehavioral organisation in securely and insecurely attached infants. Child Development, 64 (5), $1439-1450$.

13. Tseng, W -S. \& Streltzer, J. (1997). Culture \&Psychopathology. A guide to clinical assessment. New York: Brunner Mazel.

14. Weisaeth, L. \& Eitinger. L. ( 1993). Posttraumatic stress phenomena: common themes across wars, disasters and traumatic events. In J.P. Wilson, B. Raphael B (Ed.). International handbook of traumatic stress syndromes .(p. 69 - 77). New York: Plenum.

\begin{tabular}{|l|l|}
\hline Michaela Frank & $\begin{array}{l}\text { Private University College of Education of } \\
\text { the Diocese of Linz, Austria } \\
\text { Department of Continuing Education } \\
\text { Head of the M.A. Program Art Therapy } \\
\text { and Pedagogy } \\
\text { Email: Michaela1.frank@ph-linz.at }\end{array}$ \\
\hline
\end{tabular}

